\title{
A study on verbal and numerical reasoning aptitude of college going students
}

\section{Dhanashree Chavan, Veena Bhalerao and Jyoti Mankar}

Received: 18.02.2020; Revised: 10.11.2020; Accepted: 28.11 .2020

See end of the paper for authors' affiliations Dhanashree Chavan AICRP-Home Science, College of Community Science, Vasantrao Naik Marathwada Krishi

Vidyapeeth Parbhani (M.S.) India
ABSTRACT : Aptitude is a pronounced innate capacity or ability in a given line of endeavor such as a particular art, subject or vocation. The present study was done by using the Differential Aptitude Test (DAT) developed by George et al. (1947). The randomly selected sample consisted of 120 boys \& girls from all four basic faculties like Arts, Commerce, Science and Home Science in the age range 15 to 25 years. The findings of the study denoted that the verbal reasoning ability of Science students was comparatively higher than all other faculty students. The numerical ability of Commerce students reflected very low in comparison with the Home Science, Arts and Science students. There was a positive and significant correlation between the faculties of the students and their gender in verbal reasoning ability. The numerical ability of the students in the various faculty had significant negative correlation between the gender $(-0.240)$ and family size $(-0.205)$.

KEY WORDS: Aptitude, Abstract reasoning, Verbal reasoning, Numerical ability, College students

- HOW TO CITE THIS PAPER : Chavan, Dhanashree, Bhalerao, Veena and Mankar, Jyoti (2020). A study on verbal and numerical reasoning aptitude of college going students. Asian J. Home Sci., 15 (2) : 413 418, DOI: 10.15740/HAS/AJHS/15.2/413-418. Copyright@, 2020: Hind Agri-Horticultural Society. 